\title{
A Type of Diabetes Called MODY2!
}

\author{
Daniel Zamanfar* \\ Diabetes Research Center of Mazandaran, Iran \\ *Corresponding author: Daniel Zamanfar, Diabetes Research Center of Mazandaran, Iran
}

\begin{tabular}{|c|c|}
\hline ARTICLE INFO & ABSTRACT \\
\hline Received: 豐 May 01, 2021 & Abbreviations: PMH: Past Medical History; BUN: Blood Urea Nitrogen; LDL: Low-Density \\
\hline Published: 慧 May 11, 2021 & $\begin{array}{l}\text { ICA: Islet - Cell Antibodies; GAD: Glutamic Acid Decarboxylase; IGTT: Impaired Glucose } \\
\text { Tolerance Test }\end{array}$ \\
\hline
\end{tabular}

Citation: Daniel Zamanfar. A Type of Diabetes Called MODY2!. Biomed J Sci \& Tech Res 35(4)-2021. BJSTR. MS.ID.005743.

\section{Editorial}

Lack of evidence of insulin resistance, easy access to patients' clinical findings [1], age at onset of the disease, and family history of diabetes are routinely used to diagnose patients with monogenic diabetes. One of the limiting factors in diagnosis is the unavailability of genetic analysis test and its high cost, which has led to mistakenly place them in type 1 or type 2 diabetes [2]. MODY2 is a form of diabetes which its clinical findings differ significantly based on the type of mutation inherited. Its clinical findings are associated with mild or severe form in people with heterozygous inactivating or homozygous inactivating type, respectively. The severe form is classified in a group of neonatal diabetes mellitus called permanent neonatal diabetes mellitus [3,4]. However, other types of GCK gene mutations also occur with increased insulin secretion, which are associated with hypoglycemia in patients [5]. MODY2-related mutations account for approximately half of children diagnosed with incidental hyperglycemia. Most patients with MODY2 remain undiagnosed due to lack of clinical symptoms, except in places where routine screening based on examination and urinary glucose analysis is performed during periods such as school and pregnancy [6,7]. Treatment in MODY2 patients focused on pregnant cases inheriting GCK mutations because fetal growth must be controlled. In other people, however, there is no difference in the prognosis of the patients because the patients' insulin secretion level is regulated in such a way that the patients' blood glucose remains under control. In result, the mutation of these patients is resistant to pharmacological treatment and does not affect the patients' glucose homeostasis [8].
A 9-year-old boy (currently a 16-year-old boy) who came to our pediatric clinic with osmotic presentations. The patient complained of experiencing intermittent polyuria, nocturia, polydipsia that has not been associated with polyphagia. He experienced these symptoms for the first time and did not mention a history of these findings before. There were also no reports of hyperglycemia, hospitalization, and a history of underlying disease associated with the patient's complaint in the patient's past medical history (PMH). Glycemic parameters included fasting blood sugar (FBS) of $122 \mathrm{mg} / \mathrm{dl}$, hemoglobin A1c (HbA1c) of 6.2\%, and OGTT of $126 \mathrm{mg} / \mathrm{dl}$. The hyperglycemia of the patient was not associated with ketoacidosis and neurological deficits. The patient's dental examination and fundoscopy were normal. In renal analysis, blood urea nitrogen (BUN) and creatinine were $14 \mathrm{mg} / \mathrm{dl}$ and $0.7 \mathrm{mg} / \mathrm{dl}$, respectively. There was no reports of microalbuminuria, glycosuria, and ketonuria in the evaluation of the patient's urine analysis, and the urine specific gravity (U/SG) was 1009. Due to being adopted son, the history of hyperglycemia and diabetes in his family was unknown. The patient's birth weight was $3.6 \mathrm{~kg}$, and he was born by cesarean section. lipid profile such as total cholesterol of 107 $\mathrm{mg} / \mathrm{dl}(<200 \mathrm{mg} / \mathrm{dl})$, low-density lipoprotein (LDL) of $60 \mathrm{mg} /$ $\mathrm{dl}(<130 \mathrm{mg} / \mathrm{dl}$ ), high density lipoprotein (HDL) of $36 \mathrm{mg} / \mathrm{dl}$ ( $35-70 \mathrm{mg} / \mathrm{dl}$ ) and triglyceride (TG) of $50 \mathrm{mg} / \mathrm{dl}(<150 \mathrm{mg} / \mathrm{dl})$ were normal. The history of hyperlipidemia in the patient's PMH was also unclear.

Auto-antibody profile has demonstrated anti-tyrosine phosphatase ICA 512 (IA2) of 0.2 ( $\geq 7.5 \mathrm{IU} / \mathrm{mL}$ ), islet - cell 
antibodies (ICA) 0.3 ( $\geq 1 \mathrm{IU} / \mathrm{mL}$ ), anti-insulin autoantibodies (IAA) of 0.4 (> $125 \mathrm{nU} / \mathrm{mL}$ ) and anti-glutamic acid decarboxylase (GAD) of 1 ( $\geq 5 \mathrm{IU} / \mathrm{mL}$ ). The evaluation of the patient's autoimmune disorders such as markers of the thyroid diseases like graves and hashimoto, also celiac disease was negative. No findings was available for the history of autoimmune diseases in the patient's family history. The follow-up of the glycemic profile of him such as FBS, OGTT, and HbA1C ranged from (113-128mg / dl), (126-159mg / dl), and (6.1-10.7\%), respectively. The initial treatment for the patient was metformin. Due to the unknown family history, who was adopted, as well as impaired glucose tolerance test (IGTT) and fasting glucose test (IFGT), no evidence of acanthosis nigricans, negative auto-antibody profile, normal insulin level (3.3 uIU/ml), normal plasma c-peptide $(0.9 \mathrm{ng} / \mathrm{ml})$, and normal body mass index (BMI, $17.3 \mathrm{~kg} / \mathrm{m} 2$ ) the patient was genetically analyzed for MODY mutation. The genetic finding of the patient showed mutation of the GCK gene in nucleotide 1342 of chromosome 10, which was associated with the transition to $\mathrm{G}$ to A. After the determination of the MODY2 diagnosis, metformin was discontinued, and his blood glucose was controlled by diet as well as routine physical activity. It should be noted that although, the criteria for diagnosing MODY patients are non-specific, they are helpful in diagnosing cases with incidental hyperglycemia.

Rule out of MODY cases should be considered for patients with unclear family history or unclear diagnostic criteria because treatment varies greatly depending on the type of patients' MODY and is related to quality of life and complications. It can be concluded that although, each of the parameters of the criteria is helpful in achieving the MODY diagnosis, the presence or absence of one or more should not dissuade us from suspecting the MODY diagnosis.

\section{References}

1. Owen K, Shepherd M, Stride A, Ellard S, Hattersley AT (2002) Heterogeneity in young adult onset diabetes: Aetiology alters clinical characteristics. Diabetic medicine 19(9): 758-761.

2. Ellard S, Bellanné Chantelot C, Hattersley A (2008) Best practice guidelines for the molecular genetic diagnosis of maturity-onset diabetes of the young. Diabetologia 51(4): 546-553.

3. Stride A, Vaxillaire M, Tuomi T, Barbetti F, Njølstad P, et al. (2002) The genetic abnormality in the beta cell determines the response to an oral glucose load. Diabetologia 45(3): 427-435.

4. Martin D, Bellanné Chantelot C, Deschamps I, Froguel P, Robert JJ, et al. (2008) Long-term follow-up of oral glucose tolerance test-derived glucose tolerance and insulin secretion and insulin sensitivity indexes in subjects with glucokinase mutations (MODY2). Diabetes care 31(7): 1321-1323.

5. Pearson ER, Velho G, Clark P, Stride A, Shepherd M, et al. (2001) Betacell genes and diabetes: Quantitative and qualitative differences in the pathophysiology of hepatic nuclear factor-1alpha and glucokinase mutations. Diabetes 50(1): S101.

6. Estalella I, Rica I, De Nanclares GP, Bilbao JR, Vazquez JA, et al. (2007) Mutations in GCK and HNF-1 $\alpha$ explain the majority of cases with clinical diagnosis of MODY in Spain. Clinical endocrinology 67(4): 538-546.

7. Codner E, Rocha A, Deng L, Martínez Aguayo A, Godoy C, et al. (2009) Mild fasting hyperglycemia in children: high rate of glucokinase mutations and some risk of developing type 1 diabetes mellitus. Pediatric diabetes 10(6): 382-388.

8. Chakera AJ, Steele AM, Gloyn AL, Shepherd MH, Shields B, et al. (2015) Recognition and management of individuals with hyperglycemia because of a heterozygous glucokinase mutation. Diabetes care 38(7): 1383-1392.
ISSN: 2574-1241

DOI: 10.26717/BJSTR.2021.35.005743

Daniel Zamanfar. Biomed J Sci \& Tech Res

(c) (9) This work is licensed under Creative

Submission Link: https://biomedres.us/submit-manuscript.php Commons Attribution 4.0 License

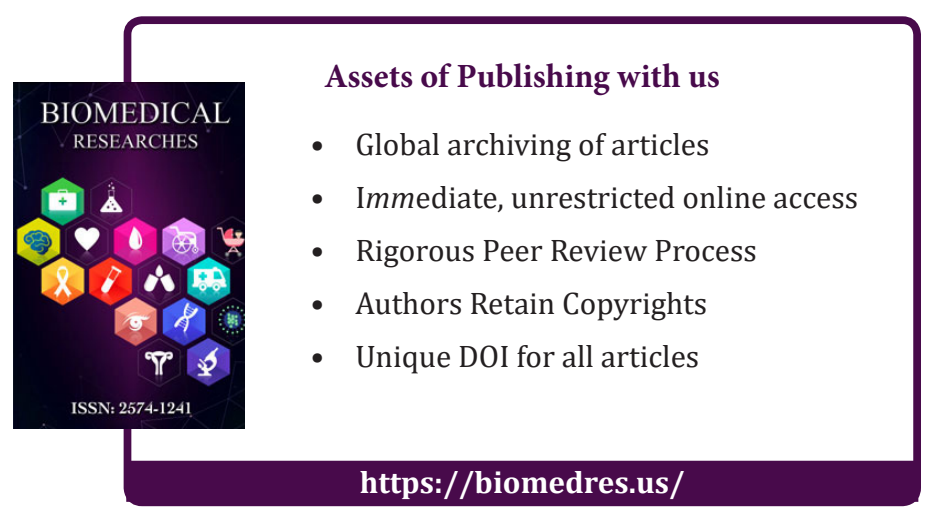

